\title{
PRAZER E SOFRIMENTO NO EXERCÍCIO GERENCIAL DO ENFERMEIRO NO CONTEXTO HOSPITALAR
}

\author{
Pleasure and suffering in nursing management in the hospital context \\ El placer y el sufrimiento en el ejercicio gerencial del enfermero en el ámbito \\ hospitalario
}

José Luís Guedes dos Santos ${ }^{1}$

Adelina Giacomelli Prochnow ${ }^{2}$

Joséte Luzia Leite ${ }^{5}$
Dalva Cezar da Silva ${ }^{3}$

Alacoque Lorenzini Erdmann ${ }^{6}$

\section{RESUMO}

Este estudo objetivou analisar os fatores de prazer e sofrimento no exercício gerencial do enfermeiro no contexto hospitalar. Tratase de uma pesquisa exploratório-descritiva com abordagem qualitativa, que utilizou como técnica de coleta a entrevista semiestruturada. Foi realizada em um hospital universitário, e os dados foram analisados mediante análise temática. Os 19 enfermeiros que participaram do estudo revelaram que a gerência é fonte de prazer quando há crescimento pessoal e profissional, reconhecimento dos colegas e satisfação do paciente; e fonte de sofrimento em função das dificuldades de relacionamento com a equipe de trabalho e da sobrecarga de trabalho. Ressalta-se a necessidade de os enfermeiros gerentes compreenderem a dualidade sofrimento e prazer na busca de um trabalho mais construtivo e realizador, por meio de maior articulação da atividade gerencial, com a experiência de vida, além do respaldo institucional e apoio dos colegas de trabalho.

Palavras-chave: Gerência. Supervisão de enfermagem. Serviço hospitalar de enfermagem. Saúde do trabalhador.

\begin{abstract}
This study aimed to analyze the factors of pleasure and suffering at work in nursing management in the hospital context. This is an exploratory-descriptive study with qualitative approach, which was used as a technique for collecting semi-structured interview. It was conducted in a university hospital and the data were analyzed using thematic analysis. The 19 nurses who participated in the study revealed that management is a source of pleasure when there is personal and professional growth, recognition and job satisfaction, and a source of suffering because of the difficulties of relationship with the team and work overload. It emphasizes the need for nurse-managers understand the duality suffering, and pleasure when seeking for a position more constructive and fulfilling, through greater coordination of management activity, with the experience of life, beyond the institutional backing and support from coworkers.
\end{abstract}

Keywords: Management. Nursing, Supervisory. Nursing Service, Hospital. Occupational Health.

\section{Resumen}

Este estudio tuvo como objetivo analizar los factores de placer y sufrimiento en el ejercicio gerencial del enfermero en el ámbito hospitalario. Investigación exploratoria-descriptiva con enfoque cualitativo, que utilizó como técnica la entrevista seme-estructurada. Se llevó a cabo en un hospital universitario y los datos fueron examinados utilizando el análisis temático. Los 19 enfermeros que participaron revelaran que la gerencia es una fuente de placer cuando hay crecimiento personal y profesional, reconocimiento y satisfacción en el trabajo, y una fuente de sufrimiento debido a las dificultades de relación con el equipo y la sobrecarga de trabajo. Se evidencia la necesidad de que los enfermeros gerentes entiendan la dualidad sufrimiento y placer de una manera más constructiva y satisfactoria, mediante una mayor coordinación de las actividades gerenciales, con la experiencia de la vida, más allá del respaldo institucional y del apoyo de sus compañeros de trabajo.

Palabras clave: Gerencia. Supervisión de Enfermería. Servicio de Enfermería en Hospital. Salud Laboral.

${ }^{1}$ Enfermeiro. Doutorando em Enfermagem do Programa de Pós-Graduação em Enfermagem da Universidade Federal de Santa Catarina. Bolsista CAPES. Integrante do Grupo de Estudos e Pesquisas em Administração, Gerência do Cuidado e Gestão Educacional em Enfermagem e Saúde (GEPADES). Florianópolis- SC. Brasil. joseenfermagem@gmail.com; ²Enfermeira. Doutora em Enfermagem. Professora do Departamento de Enfermagem da Universidade Federal de Santa Maria (UFSM). Integrante do Grupo de Pesquisas: Trabalho, Saúde, Educação e Enfermagem da UFSM. Santa Maria- RS. Brasil. agp.sma@terra.com.br; ${ }^{3}$ Enfermeira do Departamento de Enfermagem da UFSM. Mestranda em Enfermagem do Programa de Pós-Graduação em Enfermagem da UFSM (PPGenf/UFSM). Integrante do Grupo de Pesquisas: Cuidado, Saúde e Enfermagem da UFSM. Santa Maria - RS. Brasil. E-mail: dalvacezarsilva@yahoo.com.br; ${ }^{4}$ Enfermeira do Hospital Universitário de Santa Maria, Doutoranda em Enfermagem (Doutorado Interinstitucional - DINTER UNIFESP-EEAN-UFSM). Integrante do Grupo de Pesquisas: Trabalho, Saúde, Educação e Enfermagem da UFSM. Santa Maria - RS. Brasil. E-mail: cucasma@terra.com.br ${ }^{5}$ Enfermeira. Doutora em Enfermagem. Professora Titular Emérita da Universidade Federal do Estado do Rio de Janeiro. Professora do Programa de Pós-Graduação em Enfermagem da Escola de Enfermagem Anna Nery da Universidade Federal do Rio de Janeiro. Pesquisadora 1A do CNPq. Rio de Janeiro- RJ. Brasil. E-mail: joluzia@gmail.com; ${ }^{6}$ Enfermeira. Doutora em Filosofia da Enfermagem. Professora do Programa de Pós-Graduação em Enfermagem da Universidade Federal de Santa Catarina. Pesquisadora 1A do CNPq. Líder do GEPADES. Florianópolis - SC. Brasil. E-mail: alacoque@newsite.com.br 


\section{INTRODUÇÃO}

0 trabalho, a saúde e o adoecimento estão relacionados com a vida das pessoas de tal forma que a atividade laboral repercute tanto na sua saúde física quanto mental. Nesse sentido, o trabalho, que é fonte de prazer, ao mesmo tempo implica sofrimento, em maior ou menor grau, e pode trazer prejuízos à saúde dos trabalhadores ${ }^{1-2}$. No trabalho na área da saúde, isso não é diferente.

0 prazer no trabalho ocorre quando é permitido ao trabalhador desenvolver suas potencialidades, o que confere liberdade de criação e de expressão e favorece os laços cognitivos-técnicos com o resultado das atividades realizadas. Isso promove a satisfação do trabalhador por meio da conscientização de seu papel na organização em que trabalha e também para a sociedade em que está inserido².

0 sofrimento acontece quando há uma falha na intermediação entre as expectativas do trabalhador e a realidade imposta pela organização e gerência do trabalho. Dessa forma, por um lado, o sofrimento opera como um mobilizador dos investimentos para a transformação da realidade e essa possibilidade de modificar a realidade; por outro, proporciona prazer ao trabalhador ${ }^{3}$.

A relação prazer-sofrimento no trabalho do enfermeiro é uma questão explorada na literatura científica ${ }^{1,3-5}$. No entanto, os estudos que têm focalizado exclusivamente os fatores de prazer e sofrimento no exercício gerencial do enfermeiro ainda são escassos.

Nesse contexto, pode-se citar que, desde os primórdios da instituição da Enfermagem Moderna por Florence Nightingale é enfatizada a importância da função gerencial do enfermeiro e do conhecimento de administração para a profissão. No cenário hospitalar, a dimensão gerencial é predominante na atuação do enfermeiro, pois é ele o responsável pela coordenação do trabalho dos demais profissionais de enfermagem, pelo planejamento e organização do trabalho, de forma a assegurar as condições adequadas à assistência prestada aos pacientes ${ }^{6}$.

No Brasil, as atividades gerenciais nos serviços de saúde foram legalmente atribuídas aos enfermeiros pela Lei do Exercício Profissional ao estabelecer que cabe privativamente ao enfermeiro a direção, a chefia, o planejamento, a organização, a coordenação e a avaliação dos serviços de enfermagem das instituições públicas e privadas em qualquer esfera ${ }^{6-7}$.

As atribuições gerenciais dos enfermeiros também foram reconhecidas pelas diretrizes curriculares que regulamentam o ensino da enfermagem. Essas diretrizes incluem a gerência entre as competências gerais do enfermeiro, ao se referirem à tomada de decisão, liderança, administração e gerenciamento e educação permanente, o que acena para a importância e concretude do trabalho gerencial exercido pelos enfermeiros ${ }^{6,8}$.

A partir do exposto, considerando que o trabalho da enfermagem é ao mesmo tempo fonte de prazer e de sofrimento, e que o gerenciamento é uma atividade essencial e predominante na atuação do enfermeiro, questiona-se: Quais são os fatores de prazer e sofrimento no exercício gerencial do enfermeiro no contexto hospitalar? Como os enfermeiros gerentes podem potencializar os fatores de prazer e minimizar o sofrimento no trabalho?

0 objetivo deste estudo foi analisar os fatores de prazer e sofrimento no exercício gerencial do enfermeiro no contexto hospitalar.

\section{METODOLOGIA}

Trata-se de um estudo exploratório-descritivo, que percorreu a trajetória metodológica qualitativa. Esse método possibilita a busca da percepção dos fenômenos e seus significados para as pessoas, as quais estão em constante processo interativo no interior de grupos sociais dinâmicos 9 .

0 cenário da pesquisa foi um hospital universitário localizado no interior do estado do Rio Grande do Sul. A estrutura dessa organização é composta por um órgão consultivo, o Conselho de Administração, e uma Diretoria Executiva, órgão normativo e deliberativo, integrado por uma Direção Geral, Diretoria Clínica, Diretoria Administrativa, Diretoria de Enfermagem e Direção de Ensino, Pesquisa e Extensão. A Diretoria de Enfermagem abrange cinco coordenações: materno-infantil, clínica médica, cirúrgica, enfermagem em ambulatório e enfermagem em psiquiatria. Cada uma dessas coordenações abrange serviços específicos da sua área, como unidades de internação, terapia intensiva, atendimento de emergência e ambulatorial.

Quando os dados foram coletados, entre os meses de setembro e outubro de 2007, a instituição contava com cinco coordenadores de área e vinte chefes de serviço. Os coordenadores de área são enfermeiros que realizam turnos de 8 horas diárias, complementadas por plantões, a fim de cumprir a carga horária semanal, exceto sábados e domingos, dias nos quais eles folgam. Os enfermeiros responsáveis por unidade de serviços - enfermeiros gerentes ou chefes de unidade - atuam na administração e na assistência direta, realizando as atividades correspondentes concomitantemente.

0 número de participantes do estudo foi estabelecido de forma intencional entre os instituídos no cargo de chefe de serviço ou coordenador de área, com base no critério da saturação dos dados. Dessa forma, integraram a investigação 19 enfermeiros que exerciam o cargo de gerência do serviço de enfermagem da instituição e foram excluídos aqueles que estavam em férias ou licença de qualquer natureza.

A coleta de dados ocorreu por meio de entrevistas semiestruturadas com questões que enfocavam os fatores de prazer e sofrimento no exercício gerencial do enfermeiro no 
contexto hospitalar. Elas foram realizadas mediante agendamento do horário e local acordados com os participantes da pesquisa, gravadas em um dispositivo eletrônico de áudio, perfazendo entre 20 e 30 minutos de duração, e transcritas posteriormente.

A análise dos dados foi realizada por meio da técnica de análise de conteúdo temática, que se constitui de três etapas: ordenação, classificação dos dados e análise final. Na fase de ordenação, realizou-se a digitação dos dados coletados, releitura do material e ordenação dos relatos. Na classificação dos dados ocorreu a associação entre o material coletado e o referencial teórico, a partir de leitura exaustiva e repetitiva dos textos, visando à apreensão das estruturas de relevância. Na etapa de análise final, o material empírico e o teórico foram articulados de forma a obter uma interpretação e abstração do conteúdo subjacente ao que é manifestado ${ }^{10}$.

0 Comitê de Ética da instituição de referência do estudo aprovou o projeto (Processo $n^{0} 23081.010121$ / 2007-97). Os participantes assinaram um Termo de Consentimento Livre e Esclarecido formalizando sua anuência em integrar a pesquisa, conforme determina a Resolução n 196/96 do Conselho Nacional de Saúde. 0 sigilo dos informantes foi preservado por meio da adoção de códigos para identificação dos seus depoimentos ( $E 1$, $E 2, \ldots, E 19)$.

\section{RESULTADOS E DISCUSSÃO}

Os relatos dos 19 enfermeiros que participaram deste estudo possibilitaram a formação de dois temas para análise: 1) A gerência de enfermagem no contexto hospitalar como fonte de prazer, constituído por meio de duas categorias: crescimento pessoal e profissional e reconhecimento dos colegas e satisfação do paciente; e 2) A gerência de enfermagem no contexto hospitalar como fonte de sofrimento, concebido também por meio de duas categorias: dificuldades no relacionamento com a equipe de trabalho e sobrecarga de trabalho. A seguir, apresentam-se cada um desses temas e suas respectivas categorias.

\section{A gerência de enfermagem no contexto hospitalar como fonte de prazer \\ Crescimento pessoal e profissional}

0 crescimento pessoal e profissional foi mencionado pelos enfermeiros como fonte de prazer na medida em que 0 exercício gerencial representa para eles um desafio, cuja superação proporciona mais conhecimento tanto de si mesmos, quanto da estrutura organizacional da instituição hospitalar. Nesse sentido, a opção pela função gerencial aparece atrelada ao interesse individual dos enfermeiros e às características da sua personalidade, pois financeiramente ela é considerada desvantajosa. Alguns depoimentos ilustram o exposto:
[...] é um crescimento, porque, às vezes, tu tens medo de assumir um cargo administrativo, mas é um desafio e isso faz crescer porque eu estou aprendendo. Eeu gosto de desafios [risos] (E11).

Acho que é um crescimento muito grande, principalmente pelo conhecimento do hospital quando tu estás numa chefia, tu adquires o conhecimento de como funciona o hospital, e isso é muito bom (E10).

\section{[...] é muito mais pelo crescimento pessoal, porque pela parte financeira não tem retorno (E14).}

Eu nunca procurei, sempre aconteceu. Financeiramente não compensa. É pela personalidade da gente(E4).

0 exercício da gerência pode ser entendido, a partir dos depoimentos, como uma experiência diferencial de vida e como conquista da maturidade profissional, configurando-se como um desafio para os enfermeiros. 0 receio dos enfermeiros em assumir um cargo gerencial e o fato de considerarem desafiadora essa função podem estar associados à formação acadêmica da profissão, a qual é direcionada principalmente à assistência ${ }^{11}$. Além disso, a complexidade do cargo faz com que muitos enfermeiros relutem em assumi-lo $0^{12}$.

Possivelmente, as características pessoais dos enfermeiros influenciam na realização pessoal advinda da atividade gerencial, mesmo sem um retorno financeiro condizente. Nessa perspectiva, um estudo sobre a satisfação profissional dos enfermeiros evidenciou que a remuneração é um dos componentes que exerce menor influência sobre a satisfação com o trabalho ${ }^{13}$.

A experiência acumulada durante o exercício profissional e, principalmente, a partir da prática gerencial, possibilita ao enfermeiro realizar a atividade gerencial com segurança, o que pode relacionar-se com o prazer na medida em que favorece o processo de se relacionar com a equipe de trabalho, tomar decisões e assumir as responsabilidades inerentes à função desempenhada. A seguir, alguns fragmentos dos discursos dos entrevistados que são exemplos dessa constatação:

Se tu não tem segurança, não tem como se impor e se colocar. Depois de levar muito murro a gente aprende a ter mais traquejo(E2).

No início era mais medo, hoje me sinto bem( $E$ 10).

Depois de 29 anos, a gente tem mais maturidade para conversar com a equipe, se comunicar. Tu 
colocas alguma coisa que causa ansiedade tu tens mais maturidade para trabalhar, aquele jogo de cintura [risos] (E14).

A representatividade do medo, principalmente no início da atividade gerencial, denota um esforço empreendido pelas enfermeiras, gerentes de superação de dificuldades, que repercute em prazer profissional decorrente da maturidade e segurança para trabalhar. Um estudo com enfermeiras gerentes de hospitais privados também evidenciou dificuldades vivenciadas no início da carreira profissional, bem como evolução e "amadurecimento" ao longo do tempo, percebido como decorrente da vivência profissional, como conquista pelo alcance de certa maturidade na assimilação de suas atividades. As experiências relacionais de poder configuram-se como reflexo do amadurecimento e aprendizado na área gerencial e do comprometimento do enfermeiro com seu papel profissional no contexto organizacional ${ }^{14}$.

Nesse sentido, o crescimento pessoal e profissional é vivenciado pela superação do medo e das dificuldades em gerenciar no contexto hospitalar, a partir do comprometimento com a instituição. Tal comprometimento traduz-se no contato pessoal do enfermeiro gerente com outros trabalhadores e outros setores da instituição, e na responsabilidade pela equipe de enfermagem, o que contribui para o conhecimento do funcionamento da instituição hospitalar. Assim, a atividade gerencial expande a visão da amplitude do campo de atuação do enfermeiro e do próprio funcionamento da organização hospitalar.

\section{Reconhecimento dos colegas e satisfação do paciente}

Os enfermeiros percebem o prazer no exercício gerencial quando recebem retorno positivo do seu trabalho, seja pelo reconhecimento por parte dos colegas, seja pela valorização e satisfação do paciente em relação à organização e efetivação da assistência prestada.

Eu consigo contribuir bastante, não só eu, mas a equipe junto comigo. Nós conseguimos recuperar muitos funcionários que para nós antes já estariam fora da unidade. Acho que mudou alguma coisa e eu estou super feliz. E isso me faz bem, ver que mudou alguma coisa. Tem sim os momentos de estresse. Mas no geral posso dizer que estou muito satisfeita(E10).

Ver a satisfação de uma pessoa que está saindo da unidade bem atendida, quando tu vê um funcionário fazer um elogio ou fazer as coisas de forma correta. Isso tudo ébom(E 8).
É fonte de prazer quando tu propõe coisas que dão certo (E 8).

Para mim é prazeroso, não vou dizer que $100 \%$, eu trabalho com um grupo grande, com várias pessoas que pensam diferentes[...]. Existem algumas dificuldades, mas acho que é mais prazeroso. A comunicação traz prazer também(E9).

Traz prazer! [risos] mais prazer, sofrimento também, mas traz mais prazer, porque eu consigo criar alguma coisa $[\ldots](E 14)$.

0 prazer na atividade gerencial dos enfermeiros emerge, principalmente, como componente do trabalho exercido que qualifica o cuidado ao paciente no contexto hospitalar. De modo similar, pesquisa realizada com trabalhadores de enfermagem de um hospital universitário constatou que um dos principais fatores de prazer no cuidado aos idosos é a valorização do trabalho do profissional, manifestada por meio de conversa afetiva e postura motivada do idoso, e a possibilidade de interação durante os cuidados de enfermagem 4 .

Espera-se que o enfermeiro gerente esteja envolvido e comprometido com o trabalho, mas se sabe que essa situação requer atitudes e tomada de decisão diante das situações vivenciadas no contexto do trabalho. Dessa forma, a atuação desse profissional reforça meios para a otimização do trabalho, fomenta a construção de espaços e o estabelecimento de novos fluxos para 0 atendimento, 0 que possibilita maior satisfação ao enfermeiro gerente.

\section{A gerência de enfermagem no contexto hospitalar como fonte de sofrimento \\ Dificuldades no relacionamento com a equipe de trabalho}

0 exercício gerencial no contexto hospitalar é uma responsabilidade exclusiva do enfermeiro. No entanto, a gerência é um processo coletivo cujo sucesso está diretamente relacionado à cooperação e articulação do enfermeiro com a equipe de enfermagem e saúde, os gerentes/gestores da instituição e os demais trabalhadores cujas ações profissionais estão relacionadas à assistência prestada no contexto hospitalar.

Os enfermeiros expressaram que a falta de comprometimento dos colegas associada às dificuldades no relacionamento interpessoal e as constantes exigências da equipe são fatores que dificultam a gerência.

É fonte de sofrimento quando tu espera alguma coisa e não acontece [...], quando tu vê que as coisas não dão certo por questões pessoais, falta vestir mais a camiseta como se diz (E8). 
[...] tu lida com várias pessoas, e cada uma é diferente, cada uma com um jeito, tu sempre acha que está fazendo pelo certo, pelo melhor, mas não adianta tu nunca vai agradar a todos. Eaísurgem as críticas e incomodações, e eu acho que isso é que mais me estressa, me incomoda. O lidar com as pessoas eu acho que é o mais complicado da chefia (E15).

A maior dificuldade que eu tenho é com relação à direção, muitas vezes as coisas são ditas de uma forma e depois são feitas de outra (E13).

E cada um tem um temperamento, tem que ter jogo de cintura. Eu não diria que tudo isso é desgastante diante da atual conjuntura. A falta de comunicação é desgastante (E18).

A comunicação é fator que promove o desgaste do enfermeiro na atividade gerencial. Embora os enfermeiros refiram que o relacionamento com as pessoas seja uma das maiores dificuldades do exercício gerencial, esse é um atributo inerente ao cargo gerencial, o que requer desenvolvimento e aprimoramento constante das habilidades interpessoais. Além disso, também é importante a compreensão de que as dificuldades de relacionamento e os conflitos são indissociáveis das relações interpessoais e que eles podem ser inclusive salutares para o amadurecimento do grupo.

0 gerenciamento de conflitos, como parte do processo de trabalho gerencial do enfermeiro, exige que os espaços de tensão sejam mediados em prol do cuidado ao paciente e valorização da instituiçã̃o ${ }^{15}$. Por meio da mediação de conflitos são estabelecidas relações informais e consolidados laços afetivos como forma de minimizar os problemas vivenciados no cotidiano dos diferentes profissionais ${ }^{14}$. Dessa forma, o gerente ocupa importante papel na coordenação dos enfrentamentos cotidianos, seja com os pacientes/ familiares, seja com os integrantes da própria equipe de enfermagem, seja com os pares ou com a equipe multidisciplinar, além dos advindos dos demais setores do hospital' ${ }^{12}$.

Estudo analítico sobre como os conflitos se manifestam nas relações interpessoais e a magnitude que assumem no exercício gerencial do enfermeiro no contexto hospitalar evidenciou que conflitos interpessoais, envolvendo relações de caráter emotivo, ou relacionado às mais distintas manifestações de incompatibilidades que perpassam a convivência entre pessoas, são considerados pelos enfermeiros como os mais difíceis de gerenciar. É preciso descortinar as atividades do enfermeiro gerente para que a equipe se sinta coparticipante dos processos, mesmo que, em alguns momentos, como espectadora apenas; só assim ela poderá prestar solidariedade e sustentar a atuação do gerente ${ }^{16}$.

A gerência voltada para as ações de integração de cuidados e coordenação compartilhada com a equipe é imprescindível para a efetividade da administração/gerência do serviço e cuidado, bem como o envolvimento de todos os enfermeiros com os gerentes. Porém, a gerência se caracteriza como solitária, quando não é percebido o envolvimento dos enfermeiros com o enfermeiro gerente, como expressa esta depoente:

Quando eu não estava na chefia, eu vinha, fazia meu trabalho e tchau. E hoje eu vejo como os enfermeiros ainda são assim e como seria bom se todos se envolvessem, eu acho que teria que ter alguma coisa que fizesse com que todo o enfermeiro se envolvesse um pouquinho como chefe (E10).

A falta de envolvimento do enfermeiro com o trabalho do enfermeiro gerente pode influenciar no comprometimento para a efetividade de ações esperadas, o que faz com que sejam intensificadas medidas e alternativas por meio da comunicação, porém é referido que essa, quando não satisfatória, torna-se repetitiva e sem resultados. Além disso, o processo comunicativo por vezes é bloqueado, como pode ser observado no relato a seguir:

Eu acho a coisa mais dificil que se tem, porque saber se comunicar, se fazer entender e entender o outro é muito complicado (E19).

Desse modo, para o enfermeiro gerente, "fazer-se entender" é fazer com que a sua equipe realize as atividades propostas, em vez de se aproximar dela e compartilhar a necessidade de tal ação para o gerenciamento do cuidado, ou seja, a integração do cuidado, relações interpessoais e com os serviços. Além disso, ele não deve se ater apenas a transmitir informações relativas aos assuntos ligados à administração do serviço. Dessa forma, vale mencionar que o enfermeiro, na qualidade de emissor, deve buscar uma relação próxima com os integrantes da sua equipe, pois ao se comunicar, ele favorece o processo de interação social, podendo mobilizar e aproximar as pessoas visando à cooperação e integração no cotidiano de trabalho ${ }^{17}$.

Infere-se ainda que a mobilização da equipe de trabalho, conquistada com a boa comunicação, pode favorecer a diminuição da sobrecarga de trabalho, a qual é apontada com fator de sofrimento no trabalho gerencial do enfermeiro no contexto hospitalar.

\section{Sobrecarga de trabalho}

A sobrecarga de trabalho, expressa pela abrangência das atividades, pela responsabilidade em tomar decisões e pela necessidade de conciliar o cuidado direto ao paciente com atividades gerenciais, foi um fator de sofrimento citados pelos enfermeiros. 
[...] eu acho desgastante, como são várias coisas que a gente acaba vendo juntas, tem assistência, tem administração, tem escala, tem os problemas do paciente, e, às vezes, a gente não consegue fazer o verdadeiro papel desse gerenciamento, talvez a gente faça um pouquinho de tudo e não faça bem feito. [No fim ela diz, referindo-se a questão de ser chefe de unidade] dá vontade de desistir toda a hora, e, no entanto, deveria ter competitividade para isso (E3).

Eo gerenciamento aqui é sofrimento, porque tenho que fazer toda a escala geral, mais todo o gerenciamento. Abrange muita coisa e fica uma sobrecarga muito grande, e vocênão conseguefazer direito. Tem uma demanda muito grande de reuniões, de participar disso e daquilo, e o paciente fica de lado. Você vai a uma reunião das chefias e volta ao meio-dia e tem que evoluir todos os teus pacientes e ainda vê tudo o que está acontecendo. E antes de ir, tu que fazer tudo o que tu pode para deixar meio pronto e implementar isso tudo, é uma sobrecarga sobre-humana (E13).

Não me traz satisfação, eu estou nesse cargo porque não tem quem assuma o lugar. Muitas vezes traz muito sofrimento, devido à sensação de impotência, de não poder fazer as coisas. Isso traz incômodo, ansiedade, porque as pessoas acham que o chefe é o responsável por tudo, inclusive pelas ações individuais dos outros profissionais (E6).

A sobrecarga de atividades realizadas pelo enfermeiro gerente gera a sensação de que suas ações ocorrem com a menor qualidade do que realmente desejariam, o que implica cobranças pessoais, esgotamento físico e mental, repercutindo na saúde do trabalhador. A sobrecarga de trabalho foi descrita em um estudo como variável com maior predominância para o estresse nas práticas gerenciais do enfermeiro hospitalar ${ }^{18}$.

Em decorrência do esforço excessivo e da sobrecarga para o exercício da gerência, identifica-se a postura de doação, a qual somente é possível com a existência da estrutura de apoio no espaço privado. No entanto, encontra-se sentimento de orgulho, satisfação e de realização profissional quando há comprometimento com o trabalho. 0 comprometimento e o envolvimento das gerentes podem ser observados por meio da ampliação das suas responsabilidades e, por conseguinte, da necessidade de se dedicarem mais intensamente às questões organizacionais. Ainda, há o destaque da gerência na vida do enfermeiro gerente, o trabalho é priorizado em relação às demais necessidades cotidianas ${ }^{14}$.

Para amenizar o sentimento de sobrecarga de trabalho e, consequentemente, o desgaste com o trabalho gerencial, é importante que os enfermeiros estejam cientes do escopo sobre o qual recai a sua prática. No seu exercício gerencial, é comum os enfermeiros assumirem para si ou serem cobrados pela equipe de enfermagem/saúde por todas as responsabilidades sobre a gerência do cuidado e da unidade. No entanto, a gestão/ gerência de enfermagem é um processo interdisciplinar, que requer a colaboração de outros profissionais de saúde e a própria participação de outras esferas de gestão/gerência da organizacional.

0 enfermeiro é o gerente do cuidado por essência. Conciliar a gerência do cuidado com a gerência organizacional é fator que pode sobrecarregar esse profissional. Essa situação foi expressa por um enfermeiro que prefere o envolvimento com o cuidado à gerencia do seu setor.

Olha, se eu for te falar bem a verdade, é mais sofrimento do que prazer. Porque eu estou gerente agora, o meu chão mesmo é gerenciar o cuidado, estar do lado do paciente mesmo, eu nascipara ser enfermeira assistencial (E17).

A fala apresentada remete a noção de gerência como algo distante e diferente do cuidado e da assistência no exercício profissional do enfermeiro. No entanto, é importante frisar que gerência e assistência são atividades complementares, pois o enfermeiro, ao gerenciar a assistência de enfermagem, está prevendo e provendo os recursos necessários para que 0 cuidado aconteça $a^{15} .0$ gerenciamento na enfermagem abrange o cuidado de enfermagem para que ele seja pautado nas melhores práticas e de modo seguro.

0 gerenciamento do cuidado é entendido como uma ideia reguladora que pode compor o projeto de trabalho da enfermagem, à medida que permite articular as dimensões gerencial e assistencial do trabalho com foco nas necessidades de saúde do paciente e de integração do serviço, o que pode, por sua vez, promover o cuidado integral de enfermagem e a integralidade da atenção em saúde ${ }^{15}$.

Desse modo, para exercer a atividade gerencial de tal forma que ela seja fonte de prazer e saúde, é necessário que o enfermeiro receba o reconhecimento pelo trabalho realizado e que a instituição mobilize esforços para incentivar a correponsabilidade nas atividades gerenciais.

\section{CONCLUSÃO}

No exercício gerencial do enfermeiro, prazer e sofrimento não podem ser considerados polos diametralmente opostos, tampouco é possível estabelecer uma relação de equilibrio entre esses dois sentimentos, pois todo e qualquer trabalho humano, por mais prazeroso que seja, exigirá, em algum momento, embates e enfrentamentos, os quais podem se configurar como fonte de sofrimento. Portanto, é necessário que os enfermeiros 
aprendam a conviver e aceitar essa dualidade, ambiguidade e complementaridade, que é inerente à prática gerencial.

Seguindo essa linha de pensamento, este estudo sinaliza que a gerência é para o enfermeiro ora fonte de prazer, ora fonte de sofrimento. Ela é considerada fonte de prazer quando há crescimento pessoal e profissional, e quando há o reconhecimento e satisfação; e fonte de sofrimento em função das dificuldades no relacionamento com a equipe de trabalho e da sobrecarga de trabalho.

Ressalta-se a necessidade dos enfermeiros gerentes visualizarem e compreenderem a dualidade e complementaridade sofrimento e prazer em sua jornada laboral na busca de um trabalho mais construtivo e realizador, e de uma maior articulação da atividade gerencial, com a experiência de vida, além do respaldo institucional e apoio dos colegas de trabalho. Outro aspecto importante é uma delimitação mais clara das margens de atuação profissional, pois muitas vezes os enfermeiros assumem atribuições que extrapolam sua alçada e não delegam responsabilidades e atividades que poderiam ser realizadas por outros profissionais de saúde.

Sugere-se uma maior atenção dos cursos de graduação em enfermagem para a qualificação de seus egressos para o desenvolvimento das atividades gerenciais, principalmente relacionadas ao gerenciamento de conflitos e trabalho em equipe. Depois de inseridos no trabalho, para os enfermeiros trabalhadores de instituições hospitalares, faz-se importante a abertura de espaços para a discussão de questões do cotidiano laboral da equipe de enfermagem, bem como a articulação com os demais profissionais da saúde.

\section{REFERÊNCIAS}

1 Prestes FC, Beck CLC, Silva RM, Tavares JP, Camponogara S, Burg G. Prazer-sofrimento dos trabalhadores de enfermagem de um serviço de hemodiálise. Rev. gaúch. enferm. 2010 dez; 31 (4): 738-45.

2 Gomes GC, Lunardi Filho WD, Erdmann AL. 0 sofrimento psíquico em trabalhadores de UTI interferindo no seu modo de viver a enfermagem. Rev. Enferm. UERJ. 2006 jam/mar; 14(1): 93-9.

3 Mendes AM. Da psicodinâmica a psicopatologia do trabalho. In: Mendes AM, organizador. Psicodinâmica do trabalho: teoria, método e pesquisas. São Paulo: Casa do Psicólogo; 2007. p. 29-48.

4 Tavares JP, Beck CLC, Silva RM, Beuter M, Prestes FC, Rocha L. Prazer e sofrimento de trabalhadoras de enfermagem que cuidam de idosos hospitalizados. Esc Anna Nery. 2010 abr/jun; 14(2): 253-9.

5 Melo MB, Barbosa MA, Souza PR. Satisfação no trabalho da equipe de enfermagem: revisão integrativa. Rev. Latino-Am. Enfermagem. 2011;19(4): 1047-55.
6 Felli VEA, Peduzzi M; Kurcgant P, Ciampone MHT. Trabalho gerencial dos enfermeiros. In: Vale EG, Lima JR, Felli VEA, organizadoras. Programa de Atualização em Enfermagem (PROENF) - Gestão. Porto Alegre(RS): Artmed/Panamericana; 2011. p. 11-39.

7 Conselho Federal de Enfermagem. Lei n.7498 de 25 de junho de 1986: dispõe sobre a regulamentação do exercício da enfermagem e dá outras providências. Rio de Janeiro (RJ): COFEn; 1987.

8 Peres AMP, Ciampone MHT. Gerência e competências gerais do enfermeiro. Texto \& contexto enferm. 2006 jul/set; 15(3): 492-9.

9 Turato ER. Métodos qualitativos e quantitativos na área da saúde: definições, diferenças e seus objetos de pesquisa. Rev. saúde pública. 2005 jun; 39(3): 507-514.

10 Bardin L. Análise de conteúdo. Lisboa: Edições 70; 2004.

11 Martins VA, Nakao JRS, Fávero N. Atuação Gerencial do enfermeiro na perspectiva dos recém egressos do curso de enfermagem. Esc Anna Nery. 2006 abr; 10(1): 101-10.

12 Pradebon VM, Erdmann AL, Leite JL, Lima SBS, Prochnow AG. A teoria da complexidade no cotidiano da chefia de enfermagem. Acta paul. enferm. 2011; 24(1): 13-22.

13 Silva RM, Beck CLC, Guido LA, Lautert L, Tavares JP, Prestes FC. Night shift pros and cons in nursing: qualitative study. Online Braz I of Nurs. [on line]. 2009 [citado em 2010 fev 04]; 8(2). Disponível em: <http:// www.objnursing.uff.br/index.php/nursing/article/view/j.16764285.2009.2346>.

14 Brito MJM, Montenegro LC, Marília A. Experiências relacionais de poder e gênero de enfermeiras-gerente de hospitais privados. Rev. Latino-Am. Enfermagem. 2010 set/out; 18(5): 952-9.

15 Hausmann M, Peduzzi M. Articulação entre as dimensões gerencial e assistencial do processo de trabalho do enfermeiro. Texto $\&$ contexto enferm. 2009 abr/jun; 18(2): 258-65.

16 GuerraST, Prochnow AG, Trevizan MA, Guido LA. 0 conflito no exercício gerencial do enfermeiro no âmbito hospitalar. Rev. Latino-Am. Enfermagem. 2011 mar/abr; 19(2): 362-9.

17 Santos JLG, Prochnow AG, Lima SBS, Leite JL, Erdmann AL. Concepções de comunicação na gerência de Enfermagem Hospitalar entre enfermeiros gerentes de um hospital universitário. Rev. Esc. Enferm. USP. 2011 ago; 45(4): 959-65.

18 Dehan JSM, Dal Pai D, Azzolin KO. Stress and stress factors in the nurse's managerial activity. Rev enferm UFPE on line [periódico na internet]. 2011 [citado 2011 set 10] 5(4): 879-85. Disponível em: <http:// www.ufpe.br/revistaenfermagem/index.php/revista/article/view/1342>. 